\title{
La propuesta teórica del periodismo cívico y su vigencia en el escenario digital
}

Recibido: 26 de agosto de 2011

Aceptado: 20 de febrero de 2012

Publicado: 31 de octubre de 2012

\author{
Julio Mateus Borea \\ jmateus@ulima.edu.pe \\ Universidad de Lima (Perú)
}

\begin{abstract}
Resumen: La creciente presencia de Internet y las redes sociales en el sistema informativo social, así como su integración al periodismo tradicional, dan la idea de un giro en la relación entre los medios de comunicación y sus usuarios, situándolos como copartícipes en la elaboración de las agendas públicas. Sin embargo, el cambio parece centrarse en la activación de sistemas informativos paralelos, distantes de la propuesta original del periodismo cívico. El propósito de este artículo es recuperar el sentido y los planteamientos originales de esta corriente, distinguiéndola de los usos funcionales que Internet brinda a los medios de comunicación en la actualidad. Al mismo tiempo, indaga en la propuesta del modelo a nivel teórico y metodológico, rescatando los pocos casos registrados en el país.
\end{abstract}

Palabras clave: Periodismo cívico, periodismo 3.0, opinión pública, medios de comunicación y democracia.

Abstract: The growing presence of Internet and social networks into the structure of social information and their integration into traditional journalism, give the idea of a shift in the relationship between media and its users, placing them as partners in the development of public agendas. However, the change seems to focus on the activation of parallel information systems, remote from the original proposal of Civic Journalism. The purpose of this paper is to recover the meaning and the original proposals of this current, distinguishing it from functional uses that Internet provides to the media today. At the same time, investigates the model at theoretical and methodological level, rescuing the few cases performed in the country.

Key words: Civic Journalism, Journalism 3.0, Public Opinion, Media and Democracy. 


\section{Introducción}

La masificación de Internet (y más particularmente los medios sociales electrónicos) trajo consigo la idea de un cambio sustancial en el histórico contrato entre un medio de comunicación y su público consumidor. La aparición de los blogs, en la década pasada, y de los medios sociales hoy, nos ubican en un escenario de aparente transformación de los esquemas informativos. Parece asentarse la idea de una relación más democrática entre lectores, espectadores o radioescuchas con el periodismo como sistema de información pública. En efecto, como señalan muchos periodistas, los nuevos medios han dado un giro a su actividad. Pero ese giro poco tiene que ver con una interacción con el ciudadano para la creación de agendas periodísticas, y más con la facilidad de acceso a la información que el mundo digital provee a los trabajadores de la noticia.

El paradigma del flujo unidireccional (del medio al consumidor) no está en crisis: se ha reinventado y aggiornado al amparo de Internet. Si bien se consolida como tendencia la integración que hacen los medios de comunicación de medios sociales y aplicaciones interactivas a sus plataformas multimedia, la dinámica de producción de noticias y los flujos de información parecen intactos. Estos cambios propuestos por los medios de comunicación, sin embargo, se hacen bajo el inspirador rótulo de "periodismo ciudadano". Pero no debemos confundir las estrategias gracias a las cuales el usuario del medio puede publicar contenidos propios (en formatos de denuncias que, además, enfrentan dilemas éticos) con la propuesta original que el periodismo cívico planteó hace más de veinte años.

\section{Orígenes del periodismo cívico}

Este concepto y sus variantes (Public Journalism o "periodismo ciudadano") tienen su partida de nacimiento en los Estados Unidos a finales de la década de los ochenta e inicios de los noventa. Fue concebido inicialmente como un ensayo de la prensa por encontrar nuevas formas de interrelacionarse con el público. Se reconoce como "el primer movimiento generado conjuntamente desde el propio sistema de medios y desde el mundo académico que pone en tela de juicio los fundamentos mismos del lugar institucional de la profesión de informar" (Álvarez, 1999: 8).

Su surgimiento no es gratuito y es atribuido a Jay Rosen (1996), uno de los fundadores del Public Journalism, dentro de lo que denominó "las seis grandes crisis de la prensa estadounidense". La primera de estas consistiría en la legitimidad y credibilidad: las encuestas arrojaban un descenso considerable en los niveles confianza del público a la información que recibía de los medios, que en treinta años desde 1965 había descendido a la mitad. En segundo lugar, la crisis tecnológica, vinculada a la superabundancia de la oferta informativa. Tercero, la crisis política: la pésima cobertura de los medios de las elecciones presidenciales de 1988 había ocasionado que la gente pensara en ellos como parte del problema de la política nacional antes que la solución.

La cuarta crisis es la laboral: el nivel de periodistas contratados bajó en proporciones significativas y el de los que renunciaban o eran despedidos subió; se instalaron una 
angustia y ansiedad endémicas en las redacciones porque había llegado "el fin de la era de la credibilidad absoluta". En quinto lugar, una crisis espiritual; para Rosen la coyuntura estaba cuestionando de manera profunda el trabajo "de unos profesionales acomodados en la certeza del saber". Y finalmente, una crisis intelectual: nadie sabía con certeza de qué contexto, de qué interpretación y de qué análisis se hablaba al referirse a la función periodística.

Esta suma dio como resultado los primeros proyectos de periodismo cívico reconocidos como tales: "Your Vote Counts", lanzado durante las elecciones 1990 por el diario Wichita Eagle, en Kansas, que permitió elaborar con la participación de los lectores una agenda ciudadana sobre temas que debían ser discutidos por los candidatos; y "We the People", proyecto concertado por el principal diario y la televisora pública de Wisconsin para cubrir las elecciones primarias entre Bill Clinton y Jerry Brown en 1992. Rápidamente, un grupo de medios públicos y privados formaron redes y alianzas para seguir estas iniciativas, mientras que periodistas, activistas y académicos se reunían a lo largo del país para fundar organizaciones que puedan reflexionar y sistematizar estas prácticas, principalmente con el respaldo de algunas universidades.

Dos que han logrado mantenerse y crecer hasta hoy son: The Pew Center for Civic Journalism (Pew Center), definido como una "incubadora para experimentos de Periodismo cívico que permita a nuevas organizaciones crear y afinar nuevas formas de incorporar a la gente en la vida pública"; The Public Journalism Network (PJNet), "una asociación profesional de periodistas y educadores, de carácter global, cuyos miembros comparten el mismo interés en explorar y fortalecer las relaciones entre el periodismo y la democracia".

Queda claro el sentido fundacional de esta corriente, que desde sus orígenes apuesta por abandonar la idea de que los periodistas y sus públicos son espectadores de los procesos sociales y políticos. Como señala la Declaración de Principios del PJNet, se logrará cambiar el sentido al "conectar realmente la teoría y la práctica del periodismo con la teoría y la práctica de la democracia”, como veremos con más detalle luego.

\section{3. ¿Qué interpela el periodismo cívico?}

El periodismo atraviesa serias crisis de definición conceptual. No termina de reconocerse "profesión" y se siente cada vez menos "oficio". Esto no ha impedido, sin embargo, construir a lo largo de cincuenta años de presencia académica, un corpus teórico basado, en buena medida, en la sistematización de su práctica de campo y la articulación de la misma con referente epistemológicos provenientes de otras ciencias, preferentemente sociales. Existen numerosos manuales, textos, ensayos sobre sus géneros y formatos, conceptos y herramientas (cada vez con fronteras menos marcadas producto de las tendencias sinérgicas) e incluso intensos debates sobre su acción en los marcos de la democracia y la ética (Gargurevich, 2002).

Sin ánimo de ahondar en los detalles curriculares o pedagógicos, podemos partir del reconocimiento del periodismo como un producto cultural y científico, con predominancia 
del primer factor. Esto constituye, por cierto, un reto que involucra procesos educativos, profesionales o técnicos con otros económicos, políticos, culturales y sociales (Faundes, 1997: 405-418). Así como el periodismo, es complejo encontrar una definición clara sobre el periodista (más allá de "aquel que ejerce el periodismo") o incluso de quiénes lo ejercen.

Es ilustrativo leer las dos acepciones que ofrece el Diccionario de la Real Academia Española al respecto: "1. Persona legalmente autorizada para ejercer el periodismo; 2. Persona profesionalmente dedicada en un periódico o en un medio audiovisual a tareas literarias o gráficas de información o de creación de opinión". En efecto, los periodistas provienen, casi en su mitad, de campos profesionales diversos y algunos ajenos a la teoría periodística, como el derecho, la economía, la literatura o las ciencias sociales en general, cuando no, cada vez menos, autodidactas formados en la práctica misma. Las relaciones entre el mercado y la formación, como las de oferta y demanda, configuran una tensión continua y dificultan el desarrollo de percepciones más avanzadas sobre la relación del Periodismo con la sociedad (cf. Sociedad Interamericana de Prensa, 1997; World Journalism Education Congress, 2007).

No obstante, algunos teóricos interpretan el periodismo como un sistema de clasificación de la realidad que trata de proporcionarnos una imago mundi. Por consiguiente:

"Por el acto periodístico [...] se responde a la pregunta ¿qué pasa por el mundo? con un conjunto de noticias e informaciones que realmente no refieren todo lo que pasa por el mundo, sino lo más importante de lo que pasa por el mundo, en la actualidad [...] En el continente periodístico se acomodan sistemáticamente los hechos conceptuados como más importantes mediante dos operaciones matrices del Periodismo, que son las operaciones de selección y valoración” (De Aguinaga, 2001: 243).

La teoría periodística a la que nos hemos referido y la práctica periodística tradicional a la que haremos mención no están basadas en una idea única y final, sino en la suma de nociones que presenta alguna literatura especializada. Recoger conceptos e ideas servirán para contrastarlas luego con la fórmula del periodismo cívico, lo que ayudará a comprender mejor su razón de ser. Vamos a centrarnos en tres ejes: a) la objetividad y la construcción de la noticia; b) los protagonistas y las fuentes; y c) la agenda y la noción de lo público.

\section{La objetividad y la construcción de la noticia}

La teoría periodística reconoce la objetividad como su paradigma central. Probablemente junto con la neutralidad y la independencia. En esencia, esta idea se convirtió en una doctrina que apunta al distanciamiento del periodista de la realidad, del "yo enunciador" y sugiere que es posible, así, lograr un discurso aséptico y libre de cualquier subjetividad. La procura de este ideal ha devenido, según las bases del periodismo cívico, en el surgimiento de un periodismo "notarial" que da cuenta de la realidad como si fuera la realidad misma (el dogma informativo de la noticia como "espejo de la realidad"), poniéndola al margen de cualquier contaminación opinativa y otorgándole un rango de verdad absoluta. 
Algunos entendidos (Rodríguez Borges, 1998; Bastenier, 2001) conciben la objetividad como una mitificación que pone al periodista en el papel de "humilde mensajero". Dicho mito se asienta, para Rodríguez Borges (1998), en dos presupuestos:

“1) El periodista puede y debe hacer una presentación estrictamente objetiva de la realidad; y 2) de acuerdo con lo anterior, es posible separar la exposición de los hechos de su evaluación crítica. En su versión atenuada, la defensa de la objetividad se ha presentado como un desideratum ético: un ideal noble que debe guiar la labor del periodista, pero difícil de alcanzar. En su presentación más radical, la objetividad en los relatos y la separación entre hechos y opiniones es un objetivo exigible en la práctica profesional de cada día".

Bastenier (2001: 25) es tajante cuando señala que "la objetividad no existe y no hace ninguna falta que exista, porque si fuera así todos los diarios, al menos los que cumplieran con sus objetivos profesionales, darían prácticamente la misma versión de los hechos, todo habría ocurrido de forma inapelable, al margen de que luego se editorializara de la forma que fuese".

En la otra orilla, Restrepo (2001) presenta algunas conclusiones sobre la relación entre el periódico y lectores, demostrando fundamentalmente: $a$ ) que no es creíble el periodista que hace gala de no creer en nada; en cambio, aporta razones de credibilidad el que manifiesta honestamente en qué cree; $b$ ) que la objetividad mecánica sólo produce esa información simplista que reproduce los dos puntos de vista enfrentados y se lava las manos diciendo que las conclusiones corren por cuenta del lector; $c$ ) esa objetividad es la que impide ir más allá de la superficie de los hechos, para acometer su interpretación y análisis; y en conclusión $d$ ) que el énfasis en la objetividad interfiere con el conocimiento de la audiencia. Asimismo, la construcción de la noticia está basada en un esquema que moldea la realidad y la encorseta en un mecanismo limitado y limitante. La consecuencia más letal es la estandarización: todas las rupturas o conflictos (que son por definición "noticiables", hasta los más sanguinarios) son presentados en formatos semejantes.

"Estructurada en el modelo montado sobre los seis interrogantes, qué, quién, dónde, cuándo, cómo, por qué, conocidos como las ' $6 \mathrm{~W}$ ' (por su traducción al inglés), muy pronto quedaron aun más recortadas al qué, dónde y quiénes. El cómo y sus posibilidades narrativas y explicativas sobre los sucesos fueron aplazados, bien sea porque realmente no interesaba o por la falta de suficiente cultura en los periodistas para dotar a su trabajo de los componentes que lo harían más profundo, aunque quizá menos objetivo" (Miralles, 2002: 38).

Sin perjuicio de lo anterior, es inevitable mencionar que existen "esquemas", como el que plantea el periodismo de investigación y la crónica periodística, que ayudan a generar más equilibrio informativo porque utilizan una variedad mayor de fuentes, una estructura menos rígida y porque pueden seguir temas más profundos, pero estos formatos son los menos aplicados, sin duda.

Para el periodismo cívico es preciso reconocer que las noticias, lejos de constituirse en reportes objetivos de la realidad, son verdaderas reconstrucciones de esta a través de 
procesos sociales complejos basados en diversos aspectos como la institucionalización de las prácticas mediante consensos generados ante la necesidad de abatir la incertidumbre de definir lo que es noticia y lo que no, en el contexto cotidiano del periodista (De León: 2003).

En consecuencia, y de acuerdo con Victoria Camps (ápud Restrepo, 2003), lo que el buen informador debe proponerse, no es tanto ser objetivo cuanto creíble:

"Habida cuenta que la credibilidad supone un esfuerzo sostenido: no se consigue confianza ni el prestigio, de un día para otro. Esa construcción de la credibilidad resulta más exigente que el viejo imperativo de la objetividad porque demanda un esfuerzo sin pausa para buscar y obtener la verdad de los hechos, al mismo tiempo que un control de las intencionalidades".

\section{Protagonistas y fuentes}

Para el periodismo tradicional un acontecimiento noticiable contiene sólo dos versiones polares (a favor y en contra), cuando en realidad puede haber tantas como sujetos directa o indirectamente involucrados tenga el suceso. Esta bipolaridad está expresada en la presencia regular de una parte y una contraparte, un agresor y un agredido, uno que golpea $\mathrm{y}$ otro que se defiende, en términos maniqueos hollywoodenses (un bueno y un malo). Las fuentes privilegiadas son los representantes de los poderes político y económico y los técnicos que configuran una élite mediática. La prensa tiene su perito en narcotráfico, su experto en educación, su consultor en temas jurídicos. Martini (2006) sustenta este privilegio que remite al nivel de la autoridad de la fuente en tanto constituye una instancia legitimadora de una información controversial.

Como sostiene el mencionado autor (2006: 63) respecto a la elegibilidad de las fuentes, "la primera premisa es que la fuente sea 'confiable' y esté legitimada como 'creíble', por su lugar en el espacio público y sea la más adecuada para informar sobre el hecho [...] lo que vale es la proximidad al poder o al lugar donde se producen los hechos sobre los que hay que informar". Resulta obvio, sin embargo, el solo reconocimiento social del que goza una persona pública no es suficiente para convertirla en fuente: existen, además y de modo principal, criterios comerciales y políticos supeditados a la relación del medio de comunicación con círculos de poder.

Lo que cuestiona el periodismo cívico aquí es que "los ciudadanos rara vez salen como protagonistas y en su lugar se convierte al poder en espectáculo, en algo para ser observado como una realidad distante cuyas funciones competen a otros. Solamente los líderes de opinión tienen un espacio y desarrollan una relación simbiótica con los medios: suministran el material atractivo para el consumo de masas" (Miralles, 2002: 24). Como señala Alfaro (2006: 250), "en la vida política y social el ciudadano está oculto y sólo emerge con visibilidad cuando es un agresor o una víctima que genera conmiseración. Así no participa con críticas ni opiniones, menos con propuestas. Pertenece al mundo de la pasividad como un espectador que no cuenta, excepto numéricamente a través de encuestas". 
En tal sentido, los medios crean una ciudadanía invisible que ocupa, más regularmente, el papel de víctima o victimario, restringiéndole un papel activo, deliberativo y (a fin de cuentas) ciudadano. "Sigue atribuyéndoseles mayor relevancia a las noticias que surgen de fuentes oficiales o de especial notoriedad y, entre tanto, se subestima la verdad generada por los individuos anónimos o por los que no buscan notoriedad" (García Posada, 2000: 106).

No se encuentra con facilidad en la práctica periodística tradicional, un reconocimiento a otros saberes que también son parte de la vida pública. El periodismo tradicional olvida que "no sólo son importantes y trascendentes los grandes eventos de la vida social. También lo son los microeventos y episodios de la cotidianidad, que dejan constancia del aquí y ahora de la gente" (ibídem).

\section{La agenda y la noción de lo público}

Según la teoría de la agenda-setting, el término "agenda" se acuña en un sentido metafórico para expresar cómo temas considerados relevantes por los medios ocupan el mismo lugar en las agendas de la audiencia. Desde la popularización de esta teoría en el ámbito académico, se ha axiomatizado en el criterio común la infalibilidad de los medios de comunicación para crear agendas, pero además, "las personas no sólo reciben información a través de los medios sobre determinados temas o asuntos que ocurren en el mundo y son considerados prioritarios, sino que también aprenden de ellos la importancia y el énfasis que les deben dar" (Rodríguez Díaz, 2004: 15).

Como señala Cohen, citado por Bregman (1992: 212), "la prensa puede no ser exitosa la mayor parte del tiempo para decirle a la gente qué pensar, pero es sorprendentemente exitosa para decirle a sus lectores acerca de qué pensar". Miralles (2002: 40), a partir de ahí, concluye que "1) la agenda no orienta particularmente la intensidad de las actitudes de las audiencias hacia los temas seleccionados del acontecer; y 2) la preocupación central son los efectos que produce la selección del espectro de temas posibles sobre la mente de la audiencias". Muchos medios de comunicación han incorporado a su práctica cotidiana, y con más auge desde la aparición de Internet, distintos mecanismos para relacionarse con sus audiencias, entendidas no como ciudadanos, sino como receptores que complementan el espacio llenado por aplicaciones sociales variadas (sondeos, encuestas, cuestionarios, liveblogging, comentarios). Así, las versiones digitales de los medios de comunicación, sobre todo desde la masificación de Internet en ciertos ámbitos de la sociedad, presentan espacios a través de los cuales establecen una "conexión directa con sus consumidores"1.

Pero el interés común o la agenda pública como conceptos son más complejos como para depender exclusivamente de encuestas o sondeos de opinión virtuales. Para Camps

1 "Periodismo 3.0" es un concepto creado para dar cuenta del fenómeno tecnológico y su relación con el periodismo cívico. Está basado en la premisa de que se rompen las barreras físicas que hacían pensar a los inspiradores del periodismo cívico que la verdadera democracia sólo sería real en las comunidades locales. Este "periodismo 3.0" propugna la socialización de la información periodística a través de una conversación virtual en la que los participantes intervienen en el propio mensaje a través de blogs, foros de opinión, chats, wikis y demás herramientas de Internet (cf. Varela, 2004 y Meso, 2005). 
(1996: 151), “el interés común no posee un contenido previamente fijado y definido con precisión. Es la actividad política, el reconocimiento de los problemas sociales, el consenso sobre unos presupuestos, lo que va determinando el contenido del interés común". En el mismo sentido, Patrón (2005: 262) sostiene que los "espacios públicos" son el puente entre el cliente y el ciudadano. Son "instancias que permiten la participación ciudadana en términos discursivos, como ámbitos que hacen posible un debate racional sobre cuestiones de interés general y que permitan la transformación de opiniones personales (a través de la deliberación) en una genuina opinión pública”.

En esta premisa se basa el periodismo cívico que, a su vez, critica la falta del reconocimiento de una filosofía pública por parte de quienes la construyen: "No deja de resultar paradójico el hecho de que el periodismo, al ocuparse de lo que en la categoría de casi eslogan se ha llamado 'interés público informativo', al mismo tiempo insista en negar que ese concepto es y debe ser construido desde un modelo político de sociedad, que allí no entra en juego la 'objetividad', que por sí solos los hechos como materia prima del modelo informativo no son asépticos y que en términos de ética pública justamente se trata de hacer visibles los actores que inciden, las razones desde las cuales se construye y los modos en que se manifiesta ese interés público" (Miralles, 2002: 11).

Contrariamente, se cree que la producción de noticias y contenidos informativos es un proceso normado y legitimado. Como señala Martini (2000: 89), "para sistematizar los diferentes criterios que operan en la noticiabilidad se puede recurrir a dos variables básicas, el 'efecto' del acontecimiento sobre la sociedad y sobre otros medios en términos de transformaciones, y la 'cualidad' del acontecimiento en términos de trabajo periodístico y de percepción por los sujetos sociales”.

Para Miralles (1998), en el periodismo liberal o "tradicional", como hemos denominado en esta fundamentación:

"Siempre han predominado tres visiones de lo público: lo publicable, lo público como lo estatal y la identificación del espacio público físico como lo público en el ámbito urbano. Las tres ideas hacen más referencia a lo formal. El sentido de lo público restringido a lo publicable es el punto nodal de la crítica del Periodismo cívico al periodismo liberal. No es solo que en la selección de las noticias entren en juego lo que Champagne y Bourdieu denominan las 'categorías de percepción de los periodistas', sino que la actividad de los medios está pensada para este tipo de selección”.

Como propone De León (2003: 150) luego de investigar por algunos meses la rutina periodística de algunos diarios mexicanos: "problematizar la noticia, como una reconstrucción social de la realidad, necesariamente dirige la atención a entender qué tipo de acciones sociales constituidas en prácticas periodísticas llevan a cabo los informadores en la elaboración noticiosa a partir de las cuales la realidad, sea cual sea, puede ser significada, recopilada, procesada (seleccionada y jerarquizada) y, finalmente, publicada".

En consecuencia, la visión del mundo y las representaciones acerca de la realidad son el resultado de la institucionalización de las prácticas periodísticas al interior de la organización noticiosa. El periodismo cívico pone en cuestión estos criterios, en tanto son influidos por 
una serie de factores asociados, como ya hemos visto (relaciones comerciales, culturales, económicas y políticas, en suma, de relación con el poder), y repara en la posición de los periodistas como decisores últimos de lo publicable o noticiable.

No terminamos sin compartir una cita que encaja como síntesis perfecta para confirmar la presencia antagónica de lo que a lo largo de esta sección hemos llamado tan fácilmente la práctica periodística liberal o tradicional y que no es más que el cúmulo de nociones fuertemente adheridas al discurso y acción de muchos periodistas. Esta vez, en la pluma de Bastenier (2001: 29), presentando su curso de periodismo:

"En las antípodas de la visión de un periodismo salvacionista propio de presuntos pedagogos y agentes del bienestar ciudadano, este libro sostiene que nuestra profesión no puede ser una extensión del ministerio de Obras Sociales, ni el brazo más o menos armado de la obra del Padre Pío. La misión de procurar que la sociedad se conozca a sí misma y, quizá, por ese camino, como cuestión de hecho pero no como objetivo superior, contribuir al bienestar de todos ya es un esfuerzo suficientemente gigantesco como para que no haya necesidad de añadirle el pastoreo de las almas, la alfabetización del que no sabe, el socorro al que no tiene y demás tareas propiamente apostólicas, pero en absoluto periodísticas".

Esto no hace sino confirmar que el periodismo cívico no es una fórmula lírica luchando contra molinos de viento, sino una provocación a la práctica anquilosada de producir información como si se tratara de una mercancía. Es pertinente, entonces, compartir las preguntas que se hacía Patrón (2005: 262) en un foro sobre el asunto: “¿Qué queda del ideal democrático en este desplazamiento del ciudadano hacia el consumidor?, ¿qué quedará de la democracia si los gobernantes reemplazan la comunicación por la propaganda, los programas de Gobierno por 'marketing político' y la atención a las necesidades y valores por la lectura de las encuestas?”. Y añadiríamos: ¿Qué queda si el periodismo no asume una filosofía política dentro de la sociedad donde cumple una función pública y se deja llevar por los designios del mercado?

\section{La propuesta del periodismo cívico}

\subsection{Definición del modelo}

El periodismo cívico puede definirse, más que como un modelo, una práctica profesional o una corriente ideológica, como una sugestiva invitación a traspasar las fronteras del periodismo tradicional y a involucrarse en la esfera de la deliberación pública, en vez de quedarse en el registro de los hechos que otros producen. Como señala Rosen (1996: 83), uno de los fundadores de esta corriente, "ya tenemos información, ahora lo que nos hace falta es democracia”. El autor hace una pregunta clave: “¿para qué nos ocupamos de informar a un público que quizás ni siquiera existe?". Lo primero que se debe hacer, sostiene, es construir ese público. El periodismo liberal o tradicional presupone la existencia de una esfera pública funcionando, en la cual los asuntos comunes son continuamente reconocidos y discutidos. Por ello se piensa que es suficiente con presentar noticias, añadir algunos testimonios, publicar editoriales y hacer entrevistas a los funcionarios. 
El periodismo cívico aparece para superar la anacrónica visión difusionista de los medios que ubicaba al receptor como un ente pasivo dispuesto a absorber cualquiera información. Ciertamente este modelo fue desarmado hace muchos años (entre otros, por los estudiosos de la Escuela de Frankfurt) pero al periodismo, como industria y como práctica, le cuesta alejarse de ese paradigma instrumentalista.

Desde fines de los 80, en Latinoamérica, Martín-Barbero (1987) y otros teóricos acusaron nuevos valores y sentidos que podían construir los medios de comunicación como elementos democratizadores de las sociedades modernas. Armand y Michelle Mattelart (1990: 15) reflexionan al respecto de este cambio cuando sostienen que "en el horizonte se perfila otro paradigma, el del reconocimiento del sujeto y la pertinencia de una teoría que parte de las percepciones de aquel, de su subjetividad, que acoja las oscilaciones de sentido, que capte la comunicación como un proceso dialogante donde la verdad, que nunca más será única, se desprende de la intersubjetividad".

El modelo tradicional del periodismo se ve interpelado y puesto en cuestión desde las miradas críticas de disciplinas como la ciencia política o la sociología, que no reflexionaron de manera orgánica, salvo algunas excepciones, en el papel institucional de los medios y en particular del periodismo como actores políticos que inciden en la vida pública.

Sin entrar de lleno en el debate complejo del cómo se da esta incidencia, hoy existe un consenso en torno al papel de los medios de comunicación en las democracias. Casi recrean una relación de interdependencia (nadie hoy imagina política sin medios o viceversa). Sartori (2003: 88) afirma que en las democracias actuales el papel principal en la formación de la opinión pública lo desempeñan los medios de comunicación: "todo el edificio de la democracia se apoya, en último término, sobre la opinión pública y sobre una opinión que sea verdaderamente del público, que realmente nazca en el seno de los que la expresan".

Roncagliolo (2005: 8), sin embargo, habla de un proceso de "desdemocratización" que da pie a una paradoja contemporánea: nunca la democracia estuvo más extendida y a la vez, nunca fue menos intensa: "vivimos tiempos en los que la democracia (política y electoral) crece en extensión geográfica, pero disminuye en términos de la calidad de vida de los ciudadanos". Aquí es donde el ciudadano pasa a ser consumidor y el tipo de relaciones predominantes son las mediáticas. En este terreno se instala el debate en torno al rol de los medios de comunicación en general y el ejercicio del periodismo en concreto, más que la influencia que tiene sobre los públicos.

Según Lasch (1995: 81), "la democracia requiere debate público, no información. La información, generalmente preconcebida como la precondición de todo debate, no es sin embargo sino su resultado [...] Si la información no se genera en el debate público, gran parte de esa misma información será irrelevante, en el mejor de los casos, o manipuladora en el peor". Suponiendo entonces que algunos medios han conseguido erigir un modelo informativo plural y democrático, si este no supone la participación directa de los ciudadanos, no habrá cumplido su cometido a cabalidad. Es bajo estas premisas que el periodismo cívico se entiende como un compromiso necesario. 
En la declaración suscrita por los miembros de la Red de Periodismo Público en Georgia, Estados Unidos (2003) se señala: “[Los periodistas] Creemos que nuestra meta es articular claramente una filosofía pública para el periodismo, que ayude a los periodistas a profundizar su trabajo en las comunidades a las que sirven y que incentive a esos ciudadanos a cooperar más dinámicamente con los periodistas [...] Creemos que la democracia se beneficia cuando los periodistas escuchan a los ciudadanos".

En la misma línea, The Pew Center for Civic Journalism define el periodismo cívico como:

"una filosofía y un conjunto de valores basados en técnicas que reflejan ambos aspectos en la práctica periodística. En su corazón reside la creencia de que el periodismo tiene una obligación con la vida pública, una obligación que va más allá de comentar simplemente las noticias o administrar una gran cantidad de datos. La forma en que hacemos periodismo afecta la manera en que la gente vive. El periodismo puede ayudar a fortalecer una comunidad o puede hacer lo contrario".2.

Tomando como punto de partida esta concepción (el "qué”), el periodismo cívico propone algunos objetivos (el "cómo"). Es importante insistir, a efectos de comprender mejor estas ideas, que el periodismo cívico plantea fundamentos conceptuales que provienen principalmente de la filosofía política y no de los libros de redacción periodística (Miralles, 2000: 44).

\subsection{Objetivos}

El primero de sus objetivos es fortalecer el espacio público para mejorar la calidad de vida de la ciudad. Esta idea está íntimamente ligada a la consagración de la democracia participativa como el sello ideológico que hegemoniza sus acciones. Esto es, como el reconocimiento explícito de que la democracia es el modelo que garantiza el desarrollo. Ya el Informe MacBride hacía énfasis en la democratización de la información como una exigencia y un deber ciudadano. La definía como un proceso en que el individuo pasa a ser elemento activo y no un simple objeto de la comunicación, que aumenta la variedad de mensajes intercambiados así como el grado de representación social en la comunicación (UNESCO, 1980: 289). Este documento advertía que "se requiere de una gran variedad de fuentes de información y de opinión para que el ciudadano pueda documentar juiciosamente sus decisiones en los asuntos públicos. Esta diversidad constituye uno de los pilares de todo el sistema de comunicación en una sociedad democrática, y es tan necesario en el plano internacional como en el nacional" (ibídem: 51).

Como para no perder vigencia, el último Informe del Programa de las Naciones Unidas para el Desarrollo (2004: 156), redunda en la necesidad de ampliar y promover la participación de los ciudadanos en los temas públicos y comprometerlos con su entorno. El

2 Texto original en ingles: “... both a philosophy and a set of values supported by some evolving techniques to reflect both of those in your journalism. At its heart is a belief that journalism has an obligation to public life -an obligation that goes beyond just telling the news or unloading lots of facts. The way we do our journalism affects the way public life goes. Journalism can help empower a community or it can help disable it". 
mismo documento señala que coexisten varios poderes fácticos en la sociedad, pero son la empresa y los medios de comunicación los más importantes para garantizar su desarrollo.

Según la percepción general, "los medios son caracterizados como un control sin control, que cumple funciones que exceden el derecho a la información" (PNUD, 2004: 165). Fuera de cualquier discusión sobre el grado de influencia que ejercen los medios en la sociedad, lo cierto es que nadie los desconoce como un poder que sostiene la gobernabilidad del país, capaz de desestabilizar política, cultural y económicamente al Estado. En ese sentido, la propuesta del periodismo cívico tiene alguna vinculación con lo que hoy conocemos como "responsabilidad social", sucesora de los conceptos "conciencia social" (que implicaba un reconocimiento voluntario por parte de los medios de su rol dentro de la comunidad) y "compromiso social" (aparentemente ligado a la creación voluntaria de formas que coadyuven al desarrollo del país).

De ese "voluntarismo" pasamos a una instancia de deber. Otros de los grandes objetivos es alentar ciudadanos comprometidos con su entorno. El periodismo cívico aspira a convertirse en una estrategia para hacer de los ciudadanos lo que Ignacio Ramonet reclama como el "quinto poder". Un poder que lleve a cabo una "ecología de la información", un proceso democratizador que rompa con los monopolios informativos de los grandes conglomerados multimedia e imponga estándares de calidad informativa. Como señala el autor (2005: 256), "la libertad de los medios de comunicación no es más que una extensión de la libertad colectiva de expresión, fundamento de la democracia. Como tal, implica una 'responsabilidad social' y su ejercicio está por lo tanto sujeto en última instancia al control responsable de la sociedad". Al respecto, Camacho (2005) reclama la necesidad de crear lo que llama "ciudadanías comunicativas" mediante un modelo de producción y consumo de información periodística que incorpore la formación de opinión pública, la participación ciudadana, el control social y la deliberación pública, en el marco de gestación de espacios públicos democráticos.

Otro de los objetivos es mejorar la deteriorada relación entre los medios de comunicación, los periodistas y los públicos-ciudadanos, creando un acercamiento sostenido ${ }^{3}$. Este objetivo, como explica Alfaro (2006: 250) "tiene que ver con la búsqueda de un despertar de sensibilidades desde los medios, conociendo y comprendiendo mejor a la ciudadanía como su público. Y a la vez se emprende la gran tarea olvidad de contribuir a gestar lo que nos une o desune, aquello que concierne a todos y que requiere del ejercicio deliberativo para llegar a consensos, sin olvidar que las diferencias existen y que hay que entenderlas y aceptarlas. En estos pilares se erige esta línea de incidencia para hacer del periodismo una presión que convierta al desarrollo en un tema imprescindible de la agenda pública".

Esto plantea un cambio de actitud en el periodista, que renuncia a ser testigo lejano de la historia "para convertirse en un compañero del ciudadano en la construcción de la esfera pública, la aclaración del interés público y el reconocimiento de las diversas expresiones de la democracia en esos espacios para lo público que se han ido convirtiendo los medios

3 Desde hace algunos años, algunos medios de comunicación latinoamericanos han iniciado esfuerzos en este sentido a través de la publicación de Códigos de Ética, la creación de la figura del Defensor del Lector y del Televidente, entre otros ( $c f$. Restrepo, 2003). 
de comunicación y que este modo de hacer y pensar el periodismo, quiere fortalecer" (Miralles, 2000: 218)

Así, el periodismo cívico apela a la calificación de la opinión pública con el reconocimiento de las diferentes opiniones, realidades, percepciones y saberes que conviven en la sociedad, e inicia el compromiso de crear agendas recurriendo a los niveles más básicos de la ciudadanía democrática. Esto supone un cambio profundo en las prácticas periodísticas, como señala McMillan (1998: 171): "Existe una relevancia de las historias generadas en la vida local (en oposición a los servicios de agencias o sindicatos de información); la información gráfica se orienta a llamar la atención sobre los contenidos que hacen alusión a la vida pública; y el enfoque se orienta especialmente a los procesos, más que a los acontecimientos".

Finalmente, y como hemos venido arguyendo en estas páginas, el periodismo cívico y sus objetivos giran en torno a la idea de reconectar a los ciudadanos a la vida pública, yendo más allá de la limitada misión de contar noticias y registrar hechos, buscando un espacio amplio e intenso de deliberación entre quienes debieran ser los actores de cualquier democracia. Es, en suma, una herramienta política de acción frente a la pasividad a que el sistema de consumo nos está llevando.

\subsection{Metodología y fases}

La sistematización de las experiencias de periodismo cívico (cf. Miralles, 2000; Zavala, 2003 y Alfaro, 2006) ha permitido establecer una metodología y fases para las intervenciones. Cada experiencia ha encontrado un matiz particular, dependiendo del tema y de la población o la cantidad de periodistas con que se trabaje. No obstante, tomaremos las fases que nos presenta Prada Penagos (2000: 76) para ayudarnos a entender mejor en qué consiste un proyecto:

- Fase 1: identificación del problema. Se plantea cuál es el problema que afecta a una comunidad en particular y cuáles son las primeras fuentes de consulta.

- Fase 2: voces ciudadanas. Primer trabajo de campo. Se escucha a la comunidad sobre sus inquietudes, reclamos, necesidades y pensamientos en torno al problema en cuestión. Se consultan fuentes y documentación.

- Fase 3: agenda ciudadana. Se definen las aristas del problema y las posibles soluciones. Se proyectan actividades para iniciar el diálogo con la ciudadanía tales como foros, talleres, entrevistas, encuestas, llamadas telefónicas, debates públicos.

- Fase 4: diálogo público. Se realizan los primeros contactos con la ciudadanía, autoridades y funcionarios que tengan responsabilidades frente al problema.

- Fase 5: socialización del problema. Esta fase, en realidad, estará presente en todas las demás, es decir, a lo largo de la experiencia. Se trata de mantener informada a la comunidad en general sobre el trabajo que se adelanta. 
- Fase 6: deliberación ciudadana. En un nuevo contacto con los actores involucrados en el problema se definen las acciones que pueden llevar a una solución. Se asignan responsabilidades.

- Fase 7: agenda de compromisos. Una vez definidas las líneas de acción se fijan sus momentos de realización y sus actores o responsables.

- Fase 8: seguimiento. Desde el medio se hace un seguimiento sobre la forma como se concretan las soluciones.

El grado de incidencia que se logre al final estará supeditado a los factores ya mencionados (cantidad de periodistas y/o medios involucrados), pero también a cómo las autoridades políticas decidan atender y utilizar estas propuestas, habida cuenta que su razón de ser no son solamente la publicidad mediática que se les brinde, sino su utilización política. Como anota Rey (2005: 30), “aunque aún existe un uso funcional de la comunicación, se está pasando a su consideración como una dimensión central de la democracia y un elemento nuclear de la gestión pública [...] La construcción de la agenda pública es sin duda uno de esos escenarios en que se encuentran la democracia y la comunicación”.

\subsection{El periodismo cívico en el Perú}

Luego de algunas experiencias impulsadas por la Pontificia Universidad Bolivariana de Medellín y lideradas por Ana María Miralles (2000 y 2002) en Colombia, la idea fue recogida en el Perú por Rosa María Alfaro (2006) y el entonces Programa de Sociedad Civil (hoy Comunicación Política) de la Asociación de Comunicadores Sociales Calandria. La primera experiencia peruana de un proyecto de periodismo cívico vio la luz en la ciudad de Arequipa el primer mes del 2002 y se llamó "Ponle seguro al Taxi", enfocado en el problema de inseguridad urbana de asaltos en taxis de la ciudad, que afectaba tanto a los usuarios cuanto a los propios taxistas. Como expone su coordinador, "la iniciativa fue presentada a los comunicadores como una oportunidad para explorar juntos en la necesaria renovación del periodismo peruano, al brindarle nuevos elementos para acercarse a la población en un intercambio cualitativamente diferente del que propone el "periodismo liberal' y al ejercer la profesión con un sentido de responsabilidad social más acentuado" (Zavala, 2003: 6).

Posteriormente, se han realizado en el país más de 25 experiencias sistematizadas, pero no todas publicadas, con excepción de las llevadas a cabo por la ONG Calandria (2003) y el Consorcio de Universidades (2005) sobre temas diversos como: seguridad ciudadana, limpieza pública, transporte, descentralización, procesos electorales y salud.

Los balances de los proyectos son variados y están supeditados principalmente a tres factores: a) el grado de cohesión y compromiso logrado en los denominados "grupos impulsores" (grupos de periodistas profesionales convocados en las distintas ciudades donde se realizan los eventos y que trabajan articuladamente para la planificación, ejecución y seguimiento de las campañas de periodismo cívico), se han dado casos donde los medios no tenían interés en participar pero sus periodistas sí se comprometieron, ya sea 
presionando a sus gerentes y editores o desde su trabajo individual situado en el medio; b) el nivel de participación ciudadana e incidencia política que se logre:

"el problema radica en que cada intervención consigue efectos sobre la agenda pública y resultados precisos de cambio, pero no logra transformar la dinámica de producción informativa del medio"; y c) el liderazgo de alguna organización de la sociedad civil o medio de comunicación, lo que incluye su capacidad de convocatoria y los recursos con los que cuente para hacer sostenible los proyectos e intervenciones" (Alfaro, 2006: 253).

\section{Reflexión final}

Con el paso de los años, las tecnologías han logrado insertarse en el cuerpo mismo del quehacer periodístico. Que esa integración sea heterogénea e irregular, no impide que sea reconocida como una exigencia propia de los tiempos. En sucesivas investigaciones (Yezers'ka, 2012) ha quedado demostrado que el uso que los medios de comunicación peruanos dan a las herramientas interactivas que ofrecen los medios sociales son aún ajenas a las dinámicas que el periodismo cívico plantea originalmente.

Se concentran, por el contrario, en prácticas unidireccionales (transmisión de información, marketing y fidelización del usuario), lo que no agrega valor al sistema informativo; porque no se esfuerza por conversar, dialogar ni recoger de los usuarios inquietudes respecto a intereses más cercanos y trascendentes para su sociedad. El asunto es más dramático en el caso de medios locales o regionales, cuyo uso de los medios sociales se reduce a la opción de compartir contenidos.

Las tecnologías, a pesar de su potencial como herramientas de colaboración y producción de agendas periodísticas desde las demandas ciudadanas, no son la panacea. De hecho, el origen del periodismo cívico, así como los ejemplos puntuales registrados en el país, no tienen que ver con ellas. El espíritu de esta corriente, por lo tanto, va más allá del sentido funcional que los medios puedan ofrecer a través de plataformas virtuales que vayan apareciendo y reside en una dimensión política y cultural.

Es una apuesta de los medios de comunicación (y sus dueños, particularmente) por quebrar el sistema donde se hacen noticia sólo los hechos que responden a intereses particulares. Es una decisión por valorar al ciudadano como tal (más que como consumidor pasivo) y devolver al periodismo una esencia que rara vez tuvo: la de herramienta democrática.

\section{Fuentes consultadas}

- Alfaro Moreno, R. (2006). Otra brújula. Innovaciones en comunicación y desarrollo. Lima: ACS Calandria.

- Álvarez Teijeiro, C. (1999). Fundamentos teóricos del Public Journalism. Buenos Aires: Facultad de Ciencias de la Información de la Universidad Austral. 
- Bastenier, M. (2001). El blanco móvil. Curso de periodismo. Madrid: Santillana.

- Bregman, D. (1992). "La función de agenda: una problemática en transformación”. En Ferry, J.; Wolton D. y otros. El nuevo espacio público. Barcelona: Gedisa.

- Camacho Azurduy, C. (2005) "Ciudadanía y medios en América Latina: alcances y proyecciones”. Sala de Prensa, núm. 77, año VII, vol. 3. Extraída el 27/IX/2012 desde http://www.saladeprensa.org/ art594.htm

- De Aguinaga, E. (2001). "Hacia una teoría del periodismo". Estudios sobre el mensaje periodístico, núm. 7. Universidad Complutense de Madrid. Extraída el 27/IX/2012 desde http://www.ucm.es/info/emp/ Numer_07/7-5-Inve/7-5-04.htm

- De León Vásquez, S. (2003). La construcción del acontecer: análisis de las prácticas periodísticas. México D.F.: Universidad Autónoma de Aguascalientes.

- Faundes, J. (1997). "Retos que el Periodismo plantea a su investigación y enseñanza en las universidades". En Entel, A. (comp.). Periodistas: entre el protagonismo y el riesgo. Buenos Aires: Paidós.

- García Posada, J. (2000). "Dimensión ética del periodismo en la cultura urbana” En AA. VV. Periodismo y Ciudadanía. Buenos Aires: Fundación Konrad Adenauer.

- Gargurevich, J. (2002). “¿Para qué estudiar Periodismo?”. En Palestra de la Comunicación. Portal de asuntos públicos de la PUCP. Lima: Pontificia Universidad Católica del Perú. Extraída el 27/IX/2012 desde http://palestra.pucp.edu.pe/pal_ $\mathrm{com} /$ ?file=periodismo/gargurevich.$h \mathrm{tm}$

- Lasch, C. (1995). "Journalism, Publicity and the Lost Art of Argument”. En Dennis, E. (ed.). Media and Public Life. A Retrospective. Nueva York: The Freedom Forum Media Studies Center.

- Martín-Barbero, J. (1987). De los medios a las mediaciones. Comunicación, cultura y hegemonía. México D. F.: Gustavo Gili.

- Martini, S. (2000). Periodismo, noticia y noticiabilidad. Bogotá: Norma.

- Mattelart, A. y Mattelart, M. (1991). “La recepción: el retorno al sujeto”. Diálogos de la comunicación, núm. 30, pp. 10-17.

- McMillan, S. y otros (1998). "Periodismo público: ¿cómo hace la diferencia en el contenido editorial? En Lambeth, E. y otros. Assesing Public Journalism. Missouri: University of Missouri Press.

- Meso Ayerdi, K. (2005). "Periodismo ciudadano: voces paralelas a la profesión periodística". Chasqui, núm. 90, pp. 4-13.

- $\quad$ Miralles, A.

_(2002). Periodismo, opinión pública y agenda ciudadana. Bogotá: Norma.

_(ed.) (2000). Voces ciudadanas. Una idea de periodismo público. Medellín: Universidad Pontificia Bolivariana.

_(1998). “¿Qué es el Periodismo Cívico?”. Revista Foro, núm. 35. 
- Patrón, P. (2005). "Formación de la esfera pública desde la comunicación”. En Alfaro, R. Comunicación y Política en una democracia ética por construir. Lima: Veeduría de la Comunicación Social.

- Programa de las Naciones Unidas para el Desarrollo (2004). La democracia en América Latina. Hacia una democracia de ciudadanas y ciudadanos. Buenos Aires: Alfaguara.

- Prada Penagos, R. (2000). "Periodismo cívico y Academia". En AA. VV. Periodismo y Ciudadanía. Buenos Aires: Fundación Konrad Adenauer.

- Ramonet, I. (2005). "Información y democracia en la era de la globalización" En Álvarez, S. (ed.). Comunicación, Democracia y Ciudadanía. San Juan: Centro de Investigación en Comunicación de la Universidad de Puerto Rico.

- Restrepo, J.

_(2003). “En defensa del derecho a la información”. Sala de Prensa, núm. 53. Extraída el 27/IX/2012 desde http://www.saladeprensa.org/art427.htm

_(2001). “La objetividad periodística: utopía y realidad”. Chasqui, núm. 74. Extraída el 27/IX/2012 desde http://chasqui.comunica.org/restrepo74.htm

- Rey, G. (2005). “Consistencia y evaporación de los significados: las relaciones entre medios de comunicación y política". En Alfaro, R. Comunicación y Política en una democracia ética por construir. Lima: Veeduría de la Comunicación Social.

- Rodríguez Borges, R. (1998). "La objetividad periodística, un mito persistente”. Revista Latina de Comunicación Social, núm. 2. Extraída el 27/IX/2012 desde http://www.ull. es/publicaciones/ latina/z8/febrero.98.rodrigo.htm

- Rodríguez Díaz, R. (2004). Teoría de la Agenda-Setting, aplicación a la enseñanza universitaria. Madrid: Observatorio Europeo de Tendencias Sociales.

- Roncagliolo, R. (2005). "La democratización de la democracia”. En Álvarez, S. (ed.). Comunicación, Democracia y Ciudadanía. San Juan: Centro de Investigación en Comunicación de la Universidad de Puerto Rico.

- Rosen, J. (1996). Getting the connections right: Public Journalism and the troubles in the Press. Nueva York: Twentieth Century Fund Press.

- Sartori, G. (2003). ¿Qué es la democracia? Buenos Aires: Alfaguara.

- Sociedad Interamericana de Prensa (1997). Conferencia hemisférica sobre la modernización de la enseñanza del Periodismo. Illinois.

- UNESCO (1980). Un solo mundo, voces múltiples. Comunicación e información en nuestro tiempo. México D.F.: Fondo de Cultura Económica.

- Varela, J. (2004, Agosto 26). "Periodismo 3.0. Medios hiperlocales para ciudadanos activos". Blog Periodistas 21. Extraída el 27/IX/2012 desde http://periodistas21. blogspot.com/2004/08/periodismo-3.html

- Yezers'ka, L. (2012). "Las herramientas de participación en la prensa digital en Perú". En García de Torres, E. (coord.). Cartografía del periodismo participativo. Estudio 
de las herramientas de participación en la prensa digital de Argentina, Colombia, España, Estados Unidos, Israel, México, Perú, Portugal y Venezuela. Valencia: Tirant Humanidades.

- Zavala, C. (2003). Ponle seguro al taxi. Una experiencia de periodismo cívico. Lima: ACS Calandria.

\section{Páginas web}

Asociación de Comunicadores Sociales Calandria www.calandria.org

The Civic Practices Network

http://www.cpn.org/

The Pew Center for Civic Journalism

http://www.pewcenter.org/

The Public Journalism Network

http://pjnet.org/ 